\title{
Extinction of a Pavlovian-conditioned inhibitor leads to stimulus-specific inhibition
}

\author{
Cody W. Polack ${ }^{1} \cdot$ Mario A. Laborda ${ }^{1,2} \cdot$ Ralph R. Miller $^{1}$
}

Published online: 12 November 2019

(C) The Psychonomic Society, Inc. 2019

\begin{abstract}
Conditioned inhibitors have been shown to be largely unaffected by non-reinforced exposure (i.e., extinction treatment). Although excitatory associations are readily diminished by extinction treatment, so-called inhibitory associations appear to be largely immune to them. In two fear-conditioning experiments with rats, it was found that a decrease in inhibitory control can result from a massive number of extinction exposures to the inhibitor. Experiment 1 provided evidence that extinction treatment attenuated negative summation between the potential inhibitor and a transfer excitor. However, the extinction treatment had no influence on responding to the original training compound, indicating that some stimulus-specific inhibitory potential remained even after massive extinction. Experiment 2 indicated that retarded excitatory acquisition to the inhibitory stimulus observed after extinction treatment of the inhibitor is no greater than that following a similar amount of stimulus pre-exposure without prior inhibition training (i.e., latent inhibition). The findings indicate that inhibitory associations can be extinguished with large numbers of extinction trials, but they appear to be much more resistant to extinction than excitatory associations.
\end{abstract}

Keywords Extinction of conditioned inhibition $\cdot$ Stimulus specificity $\cdot$ Stimulus configuration $\cdot$ Summation test $\cdot$ Retardation test

\section{Introduction}

In contrast to conditioned excitatory stimuli, reducing the behavioral influence of conditioned inhibitory stimuli has been notoriously difficult to accomplish. In particular, the observation that inhibitory stimulus control persists after repeated exposure to the inhibitor alone (i.e., extinction treatment) was long ago identified as a critical failing of the widely cited Rescorla and Wagner (1972; R-W) model of Pavlovian conditioning (Williams, Overmier, \& LoLordo, 1992; see Miller, Barnet, \& Grahame, 1995, for a broad critique of the R-W model). The problem with the R-W model's account of conditioned inhibition is that inhibitory learning is treated as being completely symmetrical to excitatory learning based on the assumption that excitation and inhibition represent a continuum of associative strength (Rescorla, 1969; see Savastano, Cole, Barnet, \& Miller, 1999, for an account of inhibitory

Ralph R. Miller

rmiller@binghamton.edu

1 Department of Psychology, State University of New York at Binghamton, Binghamton, NY 13902-6000, USA

2 University of Chile, Santiago, Chile stimulus control that does not use negative valued associations or inhibitory associations). The R-W model represents associations between a given cue and a potential outcome as a single associative value that changes as a function of experience with the cue. A positive value reflects excitation, that is, the presentation of the cue foreshadows the occurrence of the outcome. The associative value of a cue changes from trial to trial based on the amount of total prediction error on that trial (i.e., the difference between the expected outcome and the outcome that actually occurs). Initially, a cue has little or no association with an outcome; thus, when the outcome occurs, it is highly unexpected. Under these conditions, the R-W model predicts that there will be a rather large increase in the association between the cue and the outcome (i.e., the associative strength increases). On subsequent presentations of that cue with the outcome, the occurrence of the outcome will be less unexpected, so there will be less of an increase in the association between the cue and the outcome. Although associative strength will accumulate over repeated cue-outcome pairings, the trial-to-trial change in associative strength diminishes as it approaches some asymptotic level. In this way, the R-W model accounts for the often observed decelerating acquisition curves.

The R-W model accounts for extinction of excitation in a similar fashion. An excitatory cue generates an expectation of 
the outcome, often an unconditioned stimulus (US). If the outcome does not occur, its omission is unexpected and the cue-outcome association is updated to reflect this new experience in the form of a decrease in the associative value between the cue and the outcome. With repeated presentations of the cue in the absence of the outcome, the associative value approaches zero. Extending the R-W to conditioned inhibition, one of the most common inhibitory training procedures is to intersperse reinforced trials of one cue (CS+) with nonreinforced trials of that cue in compound with the intended conditioned inhibitor (CS-), a procedure known as Pavlovianconditioned inhibition training (Pavlov, 1927). The R-W model uses a global error correction rule; therefore, the update mechanism for each trial takes into account the total associative value over all stimuli present on that trial and applies that correction term to each stimulus based on how well the total associative strength of all stimuli present predicted the actual outcome. In the case of Pavlovian-conditioned inhibition training, the CS+ will gain associative value during reinforced trials, whereas the associative values for the $\mathrm{CS}+$ and the CSwill decrease on the non-reinforced compound trials. In this way, the CS- will acquire a negative associative value. This negative associative value can be thought of as a negative expectancy of the outcome, which presents a conceptual challenge for behavioral observations because "negative expectancy as the expected absence" ordinarily necessitates an indirect measure (but, see Melchers, Wolff, \& Lachnit, 2006). The presence of the CS- with an excitor results in a decrease in the overall expectancy of the outcome because the positive expectancy based on the excitor is suppressed by the negative expectancy based on the inhibitor (i.e., negative summation; Rescorla, 1969).

The R-W model treats negative expectancy exactly like positive expectancy. Thus, when the inhibitor generates a negative expectancy in the absence of a conditioned excitor, the model generates an error because a negative outcome was expected, but only the absence of the outcome was experienced. Thereby, inhibitors are expected to "extinguish" by becoming less inhibitory through error correction in the same manner that conditioned excitors "extinguish" by becoming less excitatory through error correction. According to the R-W model, this process is engaged by repeated presentation of the inhibitor alone. In order to maintain a negative associative value, the inhibitor must be presented with an excitor of equal and opposite predictive value. Omission of the excitor when the inhibitor is presented creates a prediction error for the inhibitor that increases the associative value of that inhibitor, making it less inhibitory. Conceptually, when the inhibitor is presented in the absence of the excitor, there is no expected outcome to suppress and the model incorrectly predicts a seemingly impossible event, specifically a negative outcome (i.e., less than the absence of the outcome). This is conceptually analogous to the putative mechanism responsible for extinction of a conditioned excitor. Presenting an excitor or an inhibitor alone is expected to produce an error in prediction that is corrected by moving the associative value closer to zero.

Despite the R-W model making clear predictions regarding what should occur as a result of presenting a conditioned inhibitor alone, this finding has proven remarkably difficult to observe (Devito, \& Fowler, 1986, 1987; Lysle \& Fowler, 1985; Miller \& Schachtman, 1985; Pearce, Nicholas, \& Dickinson, 1982; Rescorla, 1982; Williams \& Overmier, 1988; Williams, Travis, \& Overmier, 1986; Witcher \& Ayres, 1984; Zimmer-Hart \& Rescorla, 1974). The resistance of an inhibitor to be attenuated through exposure to the inhibitor alone has been presented as an inherent failure of the R-W model (Miller et al., 1995). Thus, inhibitory learning does not appear to be perfectly symmetrical to excitatory learning. There are a few notable exceptions in which extinction of inhibition has been observed, but only when a sequential summation test was used (Detke 1991; Holland, \& Gory, 1986; Robbins, 1990).

Using human causal learning tasks that are similar but not identical to conventional Pavlovian preparations, Melchers et al. (2006) were successful in observing extinction of conditioned inhibition through exposure to the inhibitor alone. They used a preparation that conceptualized an outcome as a change in the hormone level of a fictitious patient. Thus, their conditioned inhibitor anticipated a decrease in the patient's hormone level. These studies examined differences between participants who were exposed to only zero and positive changes in the level of the hormone with participants who were exposed to zero and negative changes in the hormone. This preparation provided a learning task that allowed a neutral stimulus to be paired with an outcome that could either increase or decrease from some non-zero baseline level in the fictitious patient. The major deviation from prior reports was the use of an outcome that can take a meaningful negative value, such as when the patient's hormone level dipped below baseline. Beatu and Baker (2010) extended the research of Melchers et al. and found that exposure to negative hormone levels in hypothetical patients was not necessary to observe extinction of inhibition when the test question was predictive concerning the outcome, rather than inquiring of a causal cueoutcome relationship. Although Beatu and Baker's preparation is procedurally more analogous to a Pavlovian conditioning task with the outcomes being only positively present or absent, their task itself suggests the existence of a negative outcome, even if participants were never explicitly exposed to negative values of the outcome. The nature of the task implies that hormone levels exist in the patient at some nonzero value. Although some participants were not explicitly exposed to negative outcomes during training, the instructions and the participants' prior knowledge about the human body may have interacted to imply that such events were possible. 
This could have been a critical component of these unusual preparations that allowed observation of extinction of inhibition, when other preparations had failed. More generally, the $\mathrm{R}-\mathrm{W}$ model makes predictions concerning processing of unfulfilled negative expectancies that in many situations appear to be erroneous. However, when the outcomes of the task are not constrained by a zero baseline, the model does much better.

The present series was designed to test whether Pavlovianconditioned inhibition in a fear-conditioning task is truly impervious to extinction treatment, or is it merely resistant to extinction. A massive number of nonreinforced exposures to the putative conditioned inhibitor alone was administered to determine whether inhibition would persist under such extensive extinction treatment. Numerous published reports describe robust resistance to extinction of conditioned inhibition in this sort of preparation. Clearly, excitation and inhibition are not as symmetrical as the R-W model suggests; however, the problem with the R-W account may only be that it is too rigid in assuming perfect symmetry. The underlying processes may be similar, but the rate of change could be quite different for extinction of excitation and extinction of inhibition. Additionally, as seen in renewal of excitatory associations (e.g., Denniston, Chang, \& Miller, 2003), massive exposure to an inhibitor may attenuate its function as a conditioned inhibitor. First, renewal itself might be viewed as an apparent resistance of excitatory learning to be attenuated by extinction treatments when testing occurs outside of the extinction context (Bouton, \& Bolles, 1979). Denniston et al. observed that massive extinction of excitation reduced the renewal effect, indicating that massive exposure may be generally effective at attenuating persistent associative strength. Second, Bouton and King (1983) demonstrated that, when extinction of an excitor occurs in a different context from that of acquisition, the extinction context does not necessarily function as a conditioned inhibitor for a transfer excitor; yet, it is still able to effectively suppress responding to the extinguished excitor. Third, Polack, Laborda, and Miller (2012) showed that the extinction context does become a conditioned inhibitor in some circumstances, and the critical variable appears to be the total amount of exposure to the extinction context, with less exposure to the context alone contributing to the context becoming inhibitory. We suggest that collectively these findings suggest a parallel between renewal and Pavlovianconditioned inhibition. The present series was designed to explore that parallel by taking a closer look at the apparent resistance to extinction of conditioned inhibition produced using Pavlov's (1927) procedure. Renewal differs from Pavlovian-conditioned inhibition in that it involves phasic reinforcement and nonreinforcement rather than the interspersed training trials typically used in conditioned inhibition training, and the potential inhibitor during renewal is contextual rather than punctate. Here we ask whether the observation of stimulus specificity of inhibition-like learning that is established in renewal preparations informs why there has been such a challenge in observing extinction of Pavlovianconditioned inhibitors through mere exposure to the inhibitor. Thus, it is possible that inhibitors in Pavlovian conditioning preparations frequently fail to appear susceptible to extinction because insufficient extinction treatment has been administered. In the present research, we used extinction parameters adapted from Polack et al.'s (2012) exposure to the extinction context, which provided substantially more exposure than previously has been used in efforts to extinguish a punctate inhibitor. Additionally, the role of the inhibitor after extinction treatment may depend on the specific excitor used during the summation test used to assess conditioned inhibition.

\section{Experiment 1}

In Experiment 1, a massive number of extinction exposures to a potential conditioned inhibitor was administered after Pavlovian-conditioned inhibition training. Conditioned inhibition was measured with both negative summation and retarded acquisition assessments (Rescorla, 1969). Additionally, the summation test assessed conditioned inhibition with a transfer excitor as well as the original training excitor. A critical feature of this design was the control of experience between both the training excitor and the transfer excitor, such that both were used to train independent conditioned inhibitors. Each of these inhibitors received equivalent treatment throughout the experiment so that they had comparable associations with the conditioned excitors with which they were trained. Matching experience with these two excitors allowed for unbiased assessment of how well inhibition transfers across different excitors by ensuring the associative status of the training excitor and the transfer excitor were equivalent.

\section{Method}

The experiment (see Table 1) was a 2 (Extinction treatment: Ext vs. NoExt) x 3 (Summation test compound: Neutral stimulus vs. Training excitor vs. Transfer excitor) factorial design for the summation test for inhibition, followed by a shift to a 2 (Extinction treatment) $\mathrm{x} 2$ (Acquisition test stimulus) factorial design for the retarded acquisition test for inhibition. All subjects were first trained with two Pavlovian-conditioned inhibitors, each with its own excitatory training CS. Then half of the animals received massive extinction of both conditioned inhibitors, whereas the other half received no stimulus exposure. For the summation test, the extinction and no-extinction conditions were each divided into three different test conditions based on the test compound they were to receive: (a) one of the two inhibitors and its training excitor, (b) one of the two inhibitors and a transfer excitor, and (c) a neutral stimulus and 
Table 1 Design of Experiment 1

\begin{tabular}{|c|c|c|c|c|c|c|c|c|}
\hline Condition & $\begin{array}{l}\text { Accl } \\
\text { Day } 1\end{array}$ & $\begin{array}{l}\text { Acquisition } \\
\text { Ctx } 1 \\
\text { Days 2-7 }\end{array}$ & $\begin{array}{l}\text { Extinction } \\
\text { Ctx } 1 \\
\text { Days 8-17 }\end{array}$ & $\begin{array}{l}\text { Reacl } \\
\text { Ctx } 2 \\
\text { Day } 18\end{array}$ & $\begin{array}{l}\text { Sum } \\
\text { Test } \\
\text { Ctx } 2 \\
\text { Day } 19\end{array}$ & $\begin{array}{l}\text { Ret } \\
\text { Train } \\
\text { Ctx } 3 \\
\text { Day } 20\end{array}$ & $\begin{array}{l}\text { Reacl } \\
\text { Ctx } 2 \\
\text { Days 21-22 }\end{array}$ & $\begin{array}{l}\text { Ret } \\
\text { Test } \\
\text { Ctx } 2 \\
\text { Day } 23\end{array}$ \\
\hline Ext-Neutral & \multirow{6}{*}{$\begin{array}{l}\text { Ctx1: } \\
30-\min \\
\text { Ctx2: } \\
30-\min \\
1 \mathrm{~A} / 1 \mathrm{~B} \\
/ 1 \mathrm{X} / 1 \mathrm{Y} / \\
1 \mathrm{Z}\end{array}$} & \multirow{6}{*}{$\begin{array}{l}21 \mathrm{~A}-U S \text { / } \\
60 \mathrm{AX}- \\
21 \mathrm{~B}-\mathrm{US} / \\
60 \mathrm{BY}-\end{array}$} & \multirow{3}{*}{$\begin{array}{l}300 \mathrm{X}- \\
300 \mathrm{Y}-\end{array}$} & \multirow{6}{*}{$60-\min$} & $A Z$ & $4 \mathrm{Y}$-US & \multirow[t]{6}{*}{ 60-min } & $\mathrm{Y}$ \\
\hline Ext-Train & & & & & $A X$ & & & \\
\hline Ext-Transfer & & & & & AY & 4 Z-US & & Z \\
\hline NoExt-Neutral & & & \multirow[t]{3}{*}{$(\mathrm{Ctx} 1)$} & & $A Z$ & $4 \mathrm{Y}-\mathrm{US}$ & & $\mathrm{Y}$ \\
\hline NoExt-Train & & & & & $A X$ & & & \\
\hline NoExt-Transfer & & & & & $A Y$ & 4 Z-US & & Z \\
\hline
\end{tabular}

Note: Extinction of a conditioned inhibitor. X, Y, \& Z = low tone ( 500 and $520 \mathrm{~Hz}$ complex tone), white noise and clicks (6/s), counterbalanced. A and B $=$ SonAlert and flashing light $(0.25-\mathrm{s}$ on/off $)$, counterbalanced. All cues were $30-\mathrm{s}$ in duration and all auditory cues are $8 \mathrm{~dB}$. Ext $=$ extinction, NoExt $=$ no extinction, Neutral $=$ tested with excitor and a neutral stimulus $(\mathrm{AZ})$, Train $=$ tested with the training excitor and the potential inhibitor $(\mathrm{AX})$, Transfer $=$ tested with the transfer excitor for the potential inhibitor (AY), Ctx $=$ Training context, US $=0.8$-mA footshock, / indicates the different trial types were interspersed.

one of the training excitors. On a subsequent retardation test, the inhibitor not tested on the summation test was paired with the outcome (i.e., US) and then tested for behavioral control. We anticipated that our extinction treatment of the conditioned inhibitor might prove effective in attenuating inhibition of a transfer excitor. Moreover, with the extensive amount of exposure we provided in this procedure, we might be sensitive to attenuating inhibition as measured with the original training excitor, but this would likely be a weaker effect than with a transfer excitor, if it were to be observed at all. The retardation test was likely to provide little indication of whether inhibition was effectively extinguished because the extinction exposure was likely to promote latent inhibition to the inhibitor that would mask any attenuation in conditioned inhibition. We included the retardation test to verify that our initial conditioned-inhibition training procedure actually produced a conventional conditioned inhibitor.

\section{Subjects and apparatus}

Subjects were 36 male and 36 female, experimentally naive, Sprague-Dawley-descended rats obtained from our own breeding colony. Body-weight ranges were $252-341 \mathrm{~g}$ for males and 178-286 g for females. Subjects were randomly assigned to one of six groups $(n \mathrm{~s}=12)$, counterbalanced within groups for sex. The animals were individually housed in standard hanging stainless-steel wire-mesh cages in a vivarium maintained on a 16/8-h light/dark cycle. Experimental manipulations occurred near the middle portion of the light phase. The animals received free access to Purina Lab Chow, whereas water availability was limited to $30 \mathrm{~min}$ per day following a progressive water deprivation schedule initiated 4 days prior to the start of the study. From the time of weaning until the start of the study, all animals were handled for $30 \mathrm{~s}$, three times per week.
Twenty-four experimental chambers of two distinct types were used. Chamber $\mathrm{R}$ was rectangular, measuring $24.0 \mathrm{~cm}$ long, $12.5 \mathrm{~cm}$ high, and $9.0 \mathrm{~cm}$ wide. The walls and ceiling of Chamber R were clear Plexiglas, and the floor was comprised of stainless steel rods measuring $0.5 \mathrm{~cm}$ in diameter, spaced $1.3 \mathrm{~cm}$ apart (center to center). The rods were connected by NE-2 bulbs, which allowed for the delivery of a $0.5-\mathrm{s}, 0.8-\mathrm{mA}$ constant current footshock. Each of 12 copies of Chamber R was housed in a separate light- and sound-attenuating environmental isolation chamber. Each chamber was dimly illuminated by a 2$\mathrm{W}$ (nominal at $120 \mathrm{VAC}$, but driven at $60 \mathrm{VAC}$ ) incandescent house light mounted on an inside wall of the environmental chest located approximately $30 \mathrm{~cm}$ from the animal enclosure. Chamber R served as Context 1 throughout the experiment. Chamber R could be modified (i.e., Modified-R chamber) to create a different training context, Context 2 . These modifications included placing a Plexiglas floor over the steel grid, introducing a lemon odor, and placing each rat in a different instance of the $\mathrm{R}$ shaped chamber than that used as Context 1. Additionally, Modified-R chambers were equipped with a water-filled lick tube that extended $1 \mathrm{~cm}$ into a cylindrical niche, which was $4.5 \mathrm{~cm}$ in diameter, left-right centered, with its bottom $1.75 \mathrm{~cm}$ above the floor of the apparatus and $5.0 \mathrm{~cm}$ deep. In each chamber, there was a photobeam detector $1 \mathrm{~cm}$ in front of the lick tube that was triggered whenever the subject licked the tube.

Chamber V was 27-cm long, 29.5-cm high, 21.5-cm wide at the top, and $5.5-\mathrm{cm}$ wide at the bottom (i.e., it was V-shaped). The floor was comprised of two $27-\mathrm{cm}$ long plates, 2-cm wide, with a $1.5-\mathrm{cm}$ gap between the two plates. A $0.8-\mathrm{mA}, 0.5-\mathrm{s}$, constant-current footshock, produced by a high voltage AC circuit in series with a 1.0-Mohm resistor could be delivered through the metal walls and floor of the chamber. The ceiling was clear Plexiglas, the front and back walls were black Plexiglas, and the side walls were stainless steel. Each of twelve copies of Chamber V was housed in a separate light- and sound- 
attenuating environmental isolation chest. Chamber V served as Context 3 throughout the experiment.

Three 45- $\Omega$ speakers on the two side walls and the back wall of the isolation chests could deliver a click train (6/s), a complex tone (500 and $520 \mathrm{~Hz}$ presented simultaneously), and white noise, each $8 \mathrm{~dB}(\mathrm{C})$ above background. The clicks, tone, and white noise served as cues $\mathrm{X}, \mathrm{Y}$, and $\mathrm{Z}$, counterbalanced within groups. Additionally, in Contexts 1 and 2, a SonAlert was mounted on the ceiling of each environmental chest, which could present a $1900-\mathrm{Hz}, 8-\mathrm{dB}(\mathrm{C})$ above background SonAlert signal. A visual stimulus that consisted of a flashing light $(0.25 \mathrm{~s}$ on/ $0.25 \mathrm{~s}$ off $)$ could also be presented in Contexts 1 and 2 . The light was provided by a $25-\mathrm{W}$ bulb nominal at $120 \mathrm{VAC}$, but driven at $80 \mathrm{VAC}$. The bulbs were mounted on an inside wall of the environmental chest, approximately $30 \mathrm{~cm}$ from the center of the experimental chamber. The flashing light and the SonAlert served as training excitors A and B, counterbalanced within groups. Ventilation fans in each enclosure provided a constant 76$\mathrm{dB}(\mathrm{C})$ background noise. All stimuli were $30 \mathrm{~s}$ in duration. The 0.8-mA, 0.5-s footshock served as the US.

\section{Procedure (see Table 1 for the experimental design)}

Acclimation On Day 1, all rats were given 30 min of exposure to Contexts 1 and 2. During acclimation to Context 2, one 30-s exposure to each stimulus (i.e., tone, flashing light, SonAlert, clicks, and white noise) was presented in a pseudorandomized order that differed across subjects. Acclimation was intended to reduce the novelty of these contexts so that the stimuli and test context (Context 2) were familiar, thereby provoking less variability in lick baselines at test due to novelty. Additionally, acclimation to Context 1 was intended to reduce the difference in novelty between Contexts 1 and 2 that might otherwise have arisen based on Phase 2 exposure to A, $\mathrm{B}, \mathrm{X}$, and $\mathrm{Y}$ in Context 1. Finally, the presentation of each individual stimulus was intended to reduce configuring during subsequent compound training trials.

Acquisition On Days 2, 4, and 6, all rats received 90-min sessions containing seven footshock-reinforced A (or B) trials and 21 non-reinforced AX (or BY) trials in Context 1. On Days 3, 5, and 7 those subjects that received A and AX trials on Days 2, 4, and 6, now received equivalent treatment with B and BY, whereas those that received B and BY trials on Days 2,4 , and 6, received equivalent treatment with A and AX. The average intertrial interval (ITI) was $200 \mathrm{~s}$ from stimulus onset to subsequent stimulus onset. All reinforced trials coterminated with the 0.5 -s footshock. The order of $\mathrm{A} / \mathrm{AX}$ and $\mathrm{B} / \mathrm{BY}$ sessions was counterbalanced within groups.

Extinction On Days 8, 10, 12, 14, and 16, each rat in the Ext condition received 60,30 -s presentations of stimulus $\mathrm{X}$ (or Y) during a 90.5-min session in Context 1 with an average ITI of 90-s, onset to onset (i.e., 60-s offset to onset), which constituted massed extinction trials relative to much of the literature concerning efforts to extinguish a conditioned inhibitor. Rats in the Ext condition that received extinction presentations of stimulus X on Days 8, 10, 12, 14, and 16, received identical treatment with stimulus Y on Days 9, 11, 13, 15 and 17, whereas those that received extinction presentations of Y on Days 8, 10, 12, 14, and 16, received extinction of $\mathrm{X}$ on Days 9, 11, 13, 15, and 17. The order of $\mathrm{X}$ and $\mathrm{Y}$ extinction sessions was counterbalanced within groups. Rats in the NoExt condition received equivalent exposure to Context 1 during Days 8-17.

Reacclimation 1 On Day 18, rats were allowed access to water in Context 2 (the test context) for $60 \mathrm{~min}$. A context shift was introduced for testing here and in Experiment 2 below in order to limit confounding of our behavioral measure of the inhibitory status of the target cue by any possible conditioning to the training context. This session was intended to recover baseline lick latencies that may have been disrupted due to prior treatments.

Summation tests On Day 19, rats were tested in Context 2. The time for each rat to lick for 5 cumulative s (i.e., lick timer paused if the rats withdraw its snout from the light beam) was recorded. The test compound was presented once the rat had finished licking for 5 cumulative s and the time for the rat to lick an additional 5 cumulative s was recorded. Each animal received $11 \mathrm{~min}$ of continuous exposure to the test compound before being removed from the chamber. Groups NoExt-Train and Ext-Train received as the test compound AX, which had been presented during initial training, to assess summation (or configuring) between the potential inhibitor and the original training excitor. Groups NoExt-Neutral and Ext-Neutral received as the test compound AZ, which served as a control for generalization decrement. Groups NoExt-Transfer and Ext-Transfer received as the test compound AY, which assessed summation between the potential inhibitor and a transfer excitor (i.e., Inhibitor Y had been paired with excitor $\mathrm{B}$ during Pavlovian-conditioned inhibition training).

\section{Summation results and discussion}

A 2 (Extinction Treatment) x 3 (Summation Test Compound) analysis of variance (ANOVA) was conducted on the mean $\log \mathrm{s}$ that each group took to lick for a cumulative $5 \mathrm{~s}$ immediately following placement in the test context on Day 19. The $\log$ transform was done to reduce the skew that is often observed in distributions of latency scores. This analysis of the PreCS period was intended to capture any baseline differences in lick latencies that may obscure interpretation of the lick latencies following CS presentation. There were no 
differences in the PreCS lick latencies based on the main effect of Extinction Treatment, Test Compound, or the interaction, largest $F(2,66)=2.33, p s>.10$.

An identical $2 \times 3$ ANOVA was conducted on the mean log $\mathrm{s}$ that each group took to lick for 5 cumulative $\mathrm{s}$ in the presence of the test compound (Fig. 1 depicts the group means and standard errors). The $2 \times 3$ interaction between Extinction Treatment and Test compound was significant, $F(2,66)=$ $6.87, p<.05, \mathrm{MSE}=.25$, Cohen's $f=.42(90 \% \mathrm{CI}=.21$, $.63)$. A series of planned contrasts was conducted to identify the source of this interaction. Group NoExt-Neutral exhibited greater conditioned suppression than both Group NoExtTrain, $F(1,66)=21.32, p<.05$, Cohen's $f=.54(90 \% \mathrm{CI}=$ $.33, .75)$ and Group NoExt-Transfer, $F(1,66)=16.87, p<.05$, Cohen's $f=.48(90 \% \mathrm{CI}=.28, .69)$, which testifies to effective conditioned suppression of licking by both the transfer excitor and the original training excitor, and its reduction by the potential inhibitor. Notably, the inhibitor was no less effective at attenuating the transfer excitor than the training excitor, $F<1$. Conducting the analogous contrasts within the Extinction condition provided an entirely different pattern. Although Group Ext-Neutral exhibited longer lick latencies than Group ExtTrain, $F(1,66)=17.31, p<.05$, Cohen's $f=.49(90 \% \mathrm{CI}=$ $.28, .69)$, lick latencies of Group Ext-Transfer were not reliably different from Group Ext-Neutral, $F<1$. These tests indicate that following extinction treatment of the conditioned inhibitor, the potential inhibitor was no longer an effective inhibitor of transfer excitors, but still remained an effective inhibitor for the original training compound. This selective attenuation of the inhibitory potential to transfer to a novel stimulus compound was further illustrated by comparison of Ext-Train to Ext-Transfer, $F(1,66)=23.07, p<.05$, Cohen's $f$ $=.56(90 \% \mathrm{CI}=.35, .77)$, which found the putative inhibitor to be a less effective conditioned inhibitor when tested with the transfer excitor rather than the training excitor.

To directly test whether the extinction treatment selectively attenuated negative summation with the transfer excitor more so than with the training excitor, a 2 (Extinction Treatment) $\mathrm{x}$ 2 (Summation Test Compound: Train vs. Transfer) planned contrast was conducted. This interaction proved significant, $F(1,66)=9.21, p<.05$, Cohen's $f=.36(90 \% \mathrm{CI}=.15$,

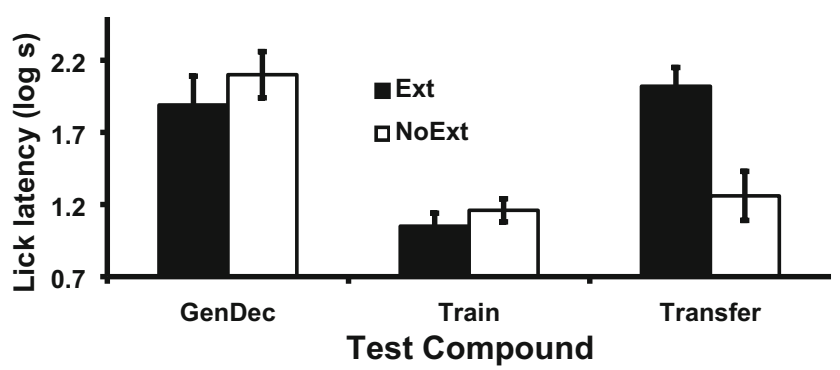

Fig. 1 Experiment 1 Summation Test mean conditioned suppression latencies in the presence of the test compounds and standard errors of the means
.56). The Extinction treatment attenuated negative summation with the transfer excitor, $F(1,66)=14.02, p<.05$, Cohen's $f=$ $.44(90 \% \mathrm{CI}=.24, .64)$, but not the training excitor, $F<1$. There appeared to be no observable impact on conditioned suppression to the original training excitor as a function of additional exposure to the inhibitor. This indicates that after massive exposure, the inhibitor still functioned as a stimulusspecific inhibitor, much like an occasion setter. However, unlike typical occasion setters, this extinguished inhibitor did not inhibit a transfer stimulus, even though the transfer excitor had been used to train a different inhibitory stimulus. Thus, the observed lingering inhibitory learning appeared to be dependent on the specific stimulus compound, that, is either an interaction between the two elemental stimuli or learning tied to their unique configural unit. In an elemental framework, any inhibitory learning to the putative inhibitor seemed to be evident only in the presence of the training excitor. Thus, the residual inhibitory learning was specific to that stimulus compound.

Retardation training On Day 20, Groups Ext-Neutral, NoExtNeutral, Ext-Transfer, and NoExt-Transfer received a 60-min session in Context 3. Again, we used a context shift here to focus on new learning occurring during the pairings of the retardation test and limit the potential roles of the training contexts in the interpretation of our observations. Rats in the Train condition were neither trained nor tested for retardation because their treatment would have been redundant with rats in the Transfer condition. Each of the four groups that underwent retardation training received four reinforced presentations of a specific cue. For Groups Ext-Transfer and NoExt-Transfer, the reinforced cue was $Z$, whereas for Groups Ext-Neutral and NoExt-Neutral, the reinforced cue was Y. Thus, retardation training occurred with a cue that had not been experienced during the summation test. Additionally, in the Neutral condition we used the inhibitor (Y), which did not have its training excitor presented during the summation test because extinction of the training excitor was previously shown to reduce the effectiveness of a Pavlovian-conditioned inhibitor (e.g., Hallam, Matzel, Sloat, \& Miller, 1990).

Reacclimation 2 On Days 21 and 22, all remaining rats received daily acclimation sessions to Context 2 for $60 \mathrm{~min}$ to recover baseline lick latencies that might have been disrupted by retardation-test training.

Retardation test On Day 23, the remaining rats were tested for conditioned lick suppression in Context 2. The time to complete 5 cumulative s of licking from the start of the test session was recorded. Each animal received presentation of the cue used in Retardation training after having completed 5 cumulative s of licking. The rat was removed 
once it had completed 5 cumulative s of licking in the presence of the auditory stimulus. Mean $\log \mathrm{s}$ to complete 5 cumulative s of licking before and during stimulus presentation were compared across groups.

\section{Retardation results and discussion}

A 2 (Extinction treatment) $\times 2$ (Test stimulus) ANOVA was conducted on the PreCS baseline lick latencies. A significant main effect of Extinction treatment was detected, with rats that were exposed to extinction of a conditioned inhibitor taking longer to complete the initial 5 cumulative s of licking in the context alone, $F(1,44)=12.33, \mathrm{p}<.05$, Cohen's $f=.50(90 \%$ $\mathrm{CI}=.25, .76)$. The main effects of Test stimulus and the interaction were not significant, $F_{\mathrm{S}}<1$.

An identical ANOVA was conducted on the 5-s lick latencies in the presence of the test stimulus (Fig. 2 depicts group means and standard error of the means). Additionally, a parallel ANCOVA, with the PreCS lick latencies used as a covariate, was used to reduce variance that could be attributed to the observed baseline difference. Although there were changes in the actual values provided by these two analyses, there was no ambiguity between the two tests in their interpretation. The ANOVA is reported below with the ANCOVA presented in parenthesis.

A main effect of Test stimulus was observed, $F(1,44)=$ $45.75, p<.05, \mathrm{MSE}=.13$, Cohen's $f=.97(90 \% \mathrm{CI}=.68$, $1.26) ;(F[1,43]=44.59, p<.05$, Cohen's $f=.96(90 \% \mathrm{CI}=$ $.67,1.25)$. Neither the main effect of Extinction treatment nor the interaction between Test stimulus and Extinction treatment were statistically significant, $F<1(F<1)$ and $F(1,44)=$ $1.14, \mathrm{p}>.29(F(1,43)=1.09, p>.30)$, respectively. In the absence of a significant interaction, the main effect of Test stimulus indicates that retarded acquisition was observed with respect to the conditioned inhibitor without any influence of the extinction manipulation. The extinction treatment appears to be ineffective at attenuating a potential inhibitor from passing a retardation test for conditioned inhibition.

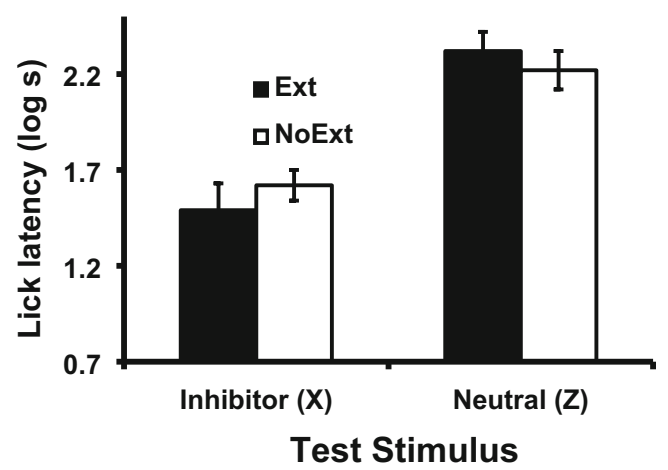

Fig. 2. Experiment 1 Retardation Test mean latencies to complete $5 \mathrm{~s}$ of licking in the presence of the test cues and standard errors of the means

\section{Summary of experiment 1}

Experiment 1 provided mixed evidence regarding whether a conditioned inhibitor may be extinguished through mere exposure to the inhibitor. Interpretation of these results depends largely on how conservative a criterion one places on defining a conditioned inhibitor. During the negative summation test, extinction of the potential inhibitor was shown to reduce negative summation between the potential inhibitor and a transfer excitor. However, the inhibitor was readily able to reduce conditioned suppression to the training excitor; in fact, it reduced suppression to the same level as if the inhibitor had not been extinguished at all. Both assessments have been used frequently in the literature, with the transfer test being the more conservative assessment. In the stricter sense, the extinction treatment seems to have attenuated the inhibitory properties of the conditioned inhibitor. Yet, the inhibitory potential of the conditioned inhibitor seemingly was not erased; rather, it was less able to generalize to a novel summation testconditioned excitor. Thus, a qualification to the statement that the inhibitor was extinguished is needed; we suggest the extinction treatment resulted in the inhibitor becoming stimulus specific.

The results of the retardation test are easier to interpret because retardation of excitatory acquisition was robust regardless of whether or not the inhibitor was extinguished. Thus, despite the extinguished inhibitor not reducing conditioned suppression to a novel transfer excitor, it remained resistant to acquiring an excitatory association itself.

An alternative account of the apparent failure of the present extinction treatment of the inhibitor to attenuate retardation of excitatory acquisition is that the inhibitor in the extinction condition may have "passed" the retardation test for conditioned inhibition, not because of the conditioned-inhibition training, but because of the massive exposure to the stimulus that occurred during extinction treatment (i.e., latent inhibition treatment; Lubow \& Moore, 1959). The neutral stimulus that was used as a control for retarded acquisition in the Extinction condition received considerably less exposure than the massively exposed inhibitor. If the massive exposure to the conditioned inhibitor was successful in attenuating conditioned inhibition, it is possible that this same treatment resulted in some latent inhibition. Therefore, the retardation test was potentially biased towards observing retarded acquisition of conditioned excitation to the extinguished inhibitor. Experiment 2 was designed to control for this potential contribution of latent inhibition during the massive extinction treatment.

\section{Experiment 2}

In Experiment 1, the potential conditioned inhibitor failed to pass a summation test with a transfer excitor (but not the 
training excitor) following massive post-training exposure (i.e., extinction treatment) to the conditioned inhibitor. In contrast, the stimulus-specific inhibitor did pass a retardation test for conditioned inhibition; however, it is possible that the extinction treatment produced sufficient latent inhibition to the target cue to produce the observed retardation effect. The design of Experiment 1 precluded discriminating between the extinction treatment failing to attenuate conditioned inhibition as assessed by a retardation test and the extinction treatment replacing conditioned inhibition with the basis of latent inhibition. These two explanations were possible because the neutral control stimulus was decidedly more novel to the subjects than was the extinguished inhibitor. To control for the potential role of latent inhibition in Experiment 2, subjects were given exposure to the neutral stimulus equivalent to that of the inhibitor during extinction treatment. Other than this change in procedure and the omission of the summation test, Experiment 2 was identical to the retardation test procedure of Experiment 1.

\section{Methods and results}

Subjects and apparatus Subjects were 24 male and 24 female, experimentally naive, Sprague-Dawley-descended rats obtained from our own breeding colony. Body-weight ranges were $182-374 \mathrm{~g}$ for males and 160-224 $\mathrm{g}$ for females. The number of subjects was reduced from that of Experiment 1 based on the effect sizes observed in Experiment 1. Subjects were randomly assigned to one of four groups ( $n \mathrm{~s}=12$ ), counterbalanced within groups for sex. Housing, apparatus, and contexts were as described in Experiment 1.

\section{Procedure (see Table 2 for the experimental design)}

Acclimation On Day 1, Acclimation to Contexts 1 and 2 were conducted as described in Experiment 1.

Acquisition On Days 2-7 all rats received Acquisition training identical to that described in Experiment 1.
Extinction On Days 8, 10, 12, 14, and 16 each rat in the Ext condition received 60 presentations of stimulus $\mathrm{X}$ during a 90.5-min session in Context 1 for an average ITI of $90 \mathrm{~s}$, onset to onset (60-s offset to onset). Rats in the Ext condition received identical treatment on Days 9, 11, 13, 15, and 17 except Stimulus Z was presented instead of Stimulus X. The actual order of $\mathrm{X}$ and $\mathrm{Z}$ sessions was counterbalanced within groups. Rats in the NoExt condition received equivalent Context 1 exposure during Days 8-17.

Retardation training On Day 18, all rats received a 60-min session in Context 3. Each group received four reinforced presentations of a specific cue. For Groups Ext-Neut and NoExt-Neut the reinforced cue was Z, whereas for Groups Ext-Inh and NoExt-Inh the reinforced cue was X.

Reacclimation On Days 19 and 20, all rats received daily acclimation sessions in Context 2 for $60 \mathrm{~min}$ in order to restabilize baseline licking.

Retardation test 1 On Day 21, rats were tested in Context 2. Each animal was presented with the cue used in Retardation training after having completed 5 cumulative s of licking. Mean $\log \mathrm{s}$ to complete 5 cumulative s of licking before and during the stimulus presentation were compared across groups.

\section{Retardation test 1 results}

A 2 (Extinction treatment: Ext vs. NoExt) x 2 (Test stimulus: Inhibitor vs. Neutral stimulus) ANOVA was conducted on the log initial latencies to lick for 5 cumulative s prior to test stimulus presentation. The two main effects and the interaction were not significant, $F_{\mathrm{s}}<1.48 . p \mathrm{~s}>.23$. An identical ANOVA was conducted on the log lick latencies during the test stimulus presentation (see Fig. 3). The critical finding is the interaction, $F(1,44)=20.29, p<.05$ Cohen's $f=.65(90 \%$ $\mathrm{CI}=.38, .91)$. Planned contrasts were conducted to identify the source of the interaction. In the NoExt condition, Group

Table 2 Design of Experiment 2

\begin{tabular}{|c|c|c|c|c|c|c|}
\hline Group & $\begin{array}{l}\text { Accl } \\
\text { Day } 1\end{array}$ & $\begin{array}{l}\text { Acquisition } \\
\text { Ctx } 1 \\
\text { Days 2-7 }\end{array}$ & $\begin{array}{l}\text { Ext } \\
\text { Ctx 1 } \\
\text { Days 8-17 }\end{array}$ & $\begin{array}{l}\text { Ret Train } \\
\text { Ctx } 3 \\
\text { Day } 18 \& \\
\text { Day } 22\end{array}$ & $\begin{array}{l}\text { Reacl } \\
\text { Ctx } 2 \\
\text { Days 19-20 \& } \\
\text { Days 23-24 }\end{array}$ & $\begin{array}{l}\text { Ret Test } \\
\text { Ctx } 2 \\
\text { Day } 21 \text { \& Day } 25\end{array}$ \\
\hline Ext-Inh & \multirow{4}{*}{$\begin{array}{l}\text { Ctx1: 30-min } \\
\text { Ctx2: } 1 \mathrm{~A} / 1 \mathrm{~B} / \\
1 \mathrm{X} / 1 \mathrm{Y} / 1 \mathrm{Z} \\
30-\min \end{array}$} & \multirow{4}{*}{$\begin{array}{l}21 \mathrm{~A}-U S \text { / } \\
60 \mathrm{AX}- \\
21 \mathrm{~B}-\mathrm{US} / \\
60 \mathrm{BY}-\end{array}$} & \multirow{2}{*}{$\begin{array}{l}300 \mathrm{X}- \\
300 \mathrm{Z}-\end{array}$} & 4 X-US & \multirow{4}{*}{ 60-min } & $\mathrm{X}$ \\
\hline Ext-Neut & & & & 4 Z-US & & Z \\
\hline NoExt-Inh & & & \multirow[b]{2}{*}{$(\mathrm{Ctx})$} & $4 \mathrm{X}-\mathrm{US}$ & & $\mathrm{X}$ \\
\hline NoExt-Neut & & & & 4 Z-US & & Z \\
\hline
\end{tabular}

Note: Retardation test (latent inhibition control). X, Y, \& Z = low tone (500 and $520 \mathrm{~Hz}$ complex tone), white noise and clicks (6/s), counterbalanced. A and $\mathrm{B}=$ SonAlert and flashing light $(0.25$-s on/off), counterbalanced. All cues were 30 -s in duration and all auditory cues are $8 \mathrm{~dB}$ above background. Ext $=$ extinction, NoExt $=$ no extinction, $\mathrm{Inh}=$ conditioned inhibitor, Neut $=$ neutral cue, $\mathrm{Ctx}=$ context of training, $\mathrm{US}=0.8 \mathrm{~mA}$ footshock, $/$ indicates the different trial types were interspersed. 


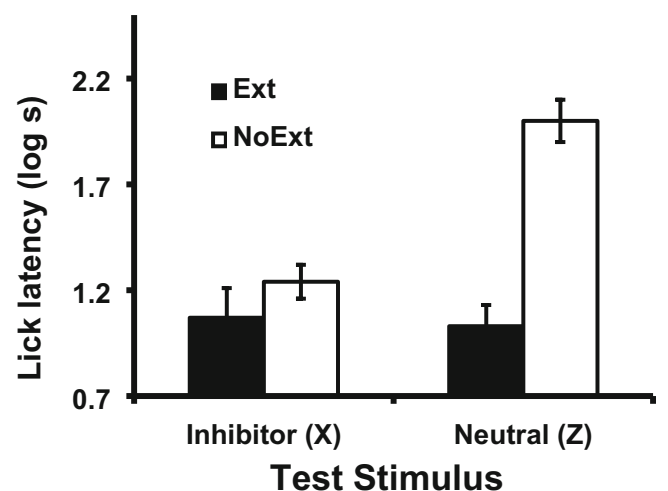

Fig. 3 Experiment 2 Retardation Test 1 mean conditioned suppression latencies in the presence of the test cues and standard errors of the means

NoExt-Inh exhibited less conditioned suppression than did Group NoExt-Neut, $F(1,44)=36.99, \mathrm{p}<.05$, Cohen's $f=$ $.87(90 \% \mathrm{CI}=.59,1.15)$, indicating that the inhibitor passed a retardation test for conditioned inhibition. In the Extinction condition, this pattern was not observed. Group Ext-Inh and Group Ext-Neut did not differ reliably, $F<1$, indicating that additional exposure to the inhibitor (i.e., extinction treatment) yielded retarded acquisition of conditioned excitation comparable to that of mere latent inhibition treatment. However, it could be argued that Group Ext-Inh did not exhibit a retardation effect when compared to Group Ext-Neut because both groups yielded a very low amount of conditioned suppression (i.e., a floor effect). The ordinal difference indicates that Group Ext-Inh was at least no more inhibitory than Group Ext-Neut; however, this is merely suggestive and requires further investigation. The level of conditioned suppression in both groups was sufficiently low that a floor effect may have obscured any real difference between Group ExtInh and Group Ext-Neut, as well as the estimates of variance in these groups. Therefore, all animals received two additional retardation training trials on $\mathrm{X}$ followed by reacclimation and a final test of conditioned suppression to the target cues. This additional training was provided in the expectation that it would increase the amount of fear conditioning, thereby avoiding floor effects for our measure of conditioned suppression.

Additional retardation training On Day 22, all rats received two additional pairings of either $\mathrm{X}$ or $\mathrm{Z}$ with the US as in the original Retardation training phase; however, stimulus onsets now occurred at 18 and 48 min into the session.

Reacclimation On Days 23 and 24, all rats received reacclimation to Context 2 as in the prior reacclimation phase.

Retardation test 2 On Day 25, all rats were tested as in the first retardation test.

\section{Retardation test 2 results}

A 2 (Extinction treatment) x 2 (Test stimulus) was conducted on the log lick latencies to complete the initial 5 cumulative $\mathrm{s}$ of licking, all $F_{\mathrm{S}}<1$. An identical ANOVA was conducted on the $\log$ lick latencies to complete 5 cumulative s of licking in the presence of the test stimulus (see Fig. 4). An interaction of Extinction treatment and Test stimulus was again detected, $F(1,44)=18.42, p<.05$, Cohen's $f=.62(90 \% \mathrm{CI}=.36$, .88). Planned contrasts were conducted to determine the source of this interaction. Massive extinction of the conditioned inhibitor in Group Ext-Inh did not reliably increase responding relative to Group NoExt-Inh, $F(1,44)=2.20, p>.14$. Group Ext-Neut exhibited more conditioned suppression than Group NoExt-Neut, indicating there was a significant amount of retarded acquisition in Group Ext-Neut, which is suggestive of latent inhibition, $F(1,44)=5.37, p<.05$, Cohen's $f=.33(90 \%$ $\mathrm{CI}=.08, .58)$. This replicates the results of the first retardation test as well as the retardation test of Experiment 1. However, comparison of Group Ext-Inh to Group Ext-Neut found conditioned suppression to be greater following massive exposure in the inhibition condition than in the neutral condition, $F(1$, $44)=5.89, p<.05$, Cohen's $f=.35(90 \% \mathrm{CI}=.10, .59)$. Alternatively stated, extinction of a conditioned inhibitor appears to yield less retardation of acquisition of excitation than did an equal amount of pre-exposure to a neutral stimulus (i.e., latent inhibition treatment). The observation that conditioned suppression was reliably higher in Group Inh-Ext indicates that the inhibitor did not function as a stronger inhibitor beyond what was seen to an equivalently pre-exposed stimulus. These findings support the interpretation that the retardation effect observed after extinction of the Pavlovian conditioned inhibitor was driven by latent inhibition acquired during the extinction treatment rather than residual conditioned inhibition.

\section{Summary of experiment 2}

Across the two retardation tests in Experiment 2, the potential conditioned inhibitor only exhibited retarded acquisition

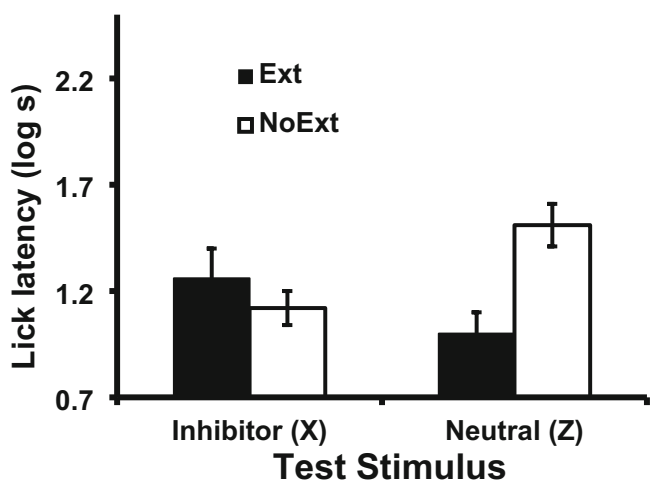

Fig. 4 Experiment 2 Retardation Test 2 mean conditioned suppression latencies in the presence of the test cues and standard errors of the means 
compared to a relatively novel stimulus. In the extinction condition, the inhibitor and the "neutral" stimulus were matched for exposure during the extinction treatment. This resulted in conditioned suppression that was either similar to (Retardation Test 1) or stronger than the inhibitor (Retardation Test 2). Apparently, massive exposure to the stimulus without inhibition training was sufficient to produce retarded acquisition, and there was no evidence that the Pavlovian-conditioned inhibition training per se was retarding subsequent acquisition. The greater suppression to the extinguished inhibitor observed during Test 2 suggests that the stimulus, having been a conditioned inhibitor, partially protected the stimulus from acquiring latent inhibition (or resulted in a type of counteraction effect, see Urcelay \& Miller, 2006). This might be a result of the inhibitor having a more complex reinforcement history than the neutral stimulus at the start of the extinction sessions.

\section{General discussion}

The present experiments provide evidence that Pavlovian conditioned inhibitors can be effectively extinguished, at least through massive exposure to the inhibitor alone (for a contemporary review of the construct of conditioned inhibition, see Sosa \& Natali, 2019). Experiment 1 found that the extinguished inhibitor no longer passed a negative summation test with a transfer excitor. Experiment 2 suggests that the extinguished inhibitor passed the retardation test not because of the conditioned inhibition training, but because of the massive exposure to the potential inhibitor prior to excitatory conditioning. This observation, in combination with that of Experiment 1, indicates that the potential inhibitor no longer functions as a conditioned inhibitor after the extinction treatment, but may instead function as a latent inhibitor. These findings suggest that the intuition of the R-W model is at least partially correct, in that inhibition can be extinguished through mere exposure. However, it seemingly takes considerably more exposure to extinguish an inhibitor than it does to extinguish an excitor.

The summation test of Experiment 1 indicated that whereas the extinguished inhibitor failed to suppress excitation to a transfer excitor, there was no observable influence of the extinction treatment on a compound of the conditioned inhibitor and the excitor with which it had been paired during inhibition training. Thus, the inhibitory properties of the conditioned inhibitor appeared to be reinstated in the presence of its training excitor. Whether the massive extinction treatment was effectively undone by presenting the inhibitor with its training excitor, or the inhibitor's potential to generalize was simply reduced, remains an open question. Additionally, the nonreinforced compound may have been partially processed as a configural unit (e.g., Pearce \& Wilson, 1991). Any inhibition acquired to the particular configural unit of the non-reinforced compound should be relatively unaffected by extinction of only one element of the compound (i.e., the inhibitor alone). In contrast, the stimulus specific inhibition observed here either relies on learning dependent on the within-compound association between the putative inhibitor and its training excitor or on learning about the unique properties of the two cues as a configural unit. Within either account, inhibition appears to remain specific to the inhibitor-training excitor compound following exposure to the inhibitor alone.

Regardless of the specific underlying mechanism that is responsible for the resistance to attenuating negative summation with the training excitor, the inhibitor itself can be empirically described as having become more stimulus-specific in its potential to suppress conditioned excitation as a consequence of extinction treatment. One might compare this stimulus-specific inhibition to that of negative modulation or negative occasion setting (e.g., Holland, 1983). The fundamental characteristic of an occasion setter is that it modulates the associations between other stimuli and does not necessarily have any direct associative value with the US. This is usually accomplished through sequential presentation of the occasion setter followed by the conditioned stimulus. This procedural change prevents the occasion setter from becoming directly linked to the outcome and is thought to enter into a hierarchical relationship wherein the occasion setter determines or "sets the occasion" for how the organism responds to the conditioned stimulus (Holland, 1989). Thus, a negative occasion setter readily suppresses responding to the CS that it sets the occasion for, but not to novel excitors that have not previously been occasion set. In contrast, conditioned inhibitors readily generalize to novel conditioned excitors due to their direct suppression of the US representation, whereas an occasion setter has a more indirect role in modifying the response-eliciting potential of a CS. The primary distinction between the stimulus-specific inhibition observed in the summation test of Experiment 1 and occasion setters is that the transfer excitor should have also been modulated by the occasion setter since it had received identical treatment (Holland \& Lamarre, 1984; Lamarre \& Holland, 1987). Although it might be argued that extinguished conditioned inhibitors merely retain the functionality of occasion setters, the data here suggest that the inhibitory properties of a stimulus following massive extinction are even more stimulus-specific than those of the typical negative occasion setter.

Lotz and Lachnit (2009) previously demonstrated extinction of a conditioned inhibitor when the outcome (e.g., the US) was a stimulus that could meaningfully take negative values as well as positive values (e.g., a circulating hormone that has a non-zero baseline value). They concluded that extinction of conditioned inhibition required outcomes that were not constrained to zero and positive values. Although bivalent outcomes may facilitate extinction of conditioned inhibition, the present observations demonstrate that, even with more 
conventional outcomes with a zero baseline value, extinction of conditioned inhibition can occur given large numbers of sufficiently massed extinction trials. The present experiments were not designed to illuminate why large numbers of relatively massed extinction trials encourage extinction of conditioned inhibition. But at least one possible reason is that massed extinction trials favor the development of strong inhibitor-extinction context associations that, in some models of conditioning, downward modulate stimulus control by the inhibitor (e.g., Stout \& Miller's, 2007 SOCR model). That is, a comparator account of conditioned inhibition relies on the putative conditioned inhibitor's activation of the training excitor as a comparison stimulus at test. Extinction of a conditioned inhibitor in SOCR would be produced by additional exposure to the conditioned inhibitor alone through both an erasure mechanism of the association between the inhibitor and the excitor and through a second-order comparison process involving the training context that would increasingly down modulate the activation of the excitor by the putative inhibitor.

Our findings in this series suggest that conditioned inhibition may indeed be extinguished much like we see excitation is extinguished. However, some qualifiers are in order. We are not suggesting a revival of the view that excitation and inhibition are equivalent processes with opposing signs. The traditional R-W account of conditioned inhibition is still challenged by the observation that extinction of inhibition proceeds so much slower than extinction of excitation, and additionally by why extinction of conditioned inhibition when it does occur is limited to attenuation of negative summation with transfer excitors, but not the original training excitor. One possible account is that the context used for inhibitory training itself may be somewhat excitatory. Perhaps an excitatory context serves to provide sufficient background expectation of the US to protect the inhibitor from extinction at least until sufficient exposure to the context has been given. This could explain our findings in the present series because we provided acquisition and extinction in the same context. A future assessment of this account could attempt extinction of the conditioned inhibitor in a distinctly different context from that of inhibitory training. Additionally, any account that relies on within-compound associations between the inhibitor and training excitor should offer insight into the asymmetry between extinction of excitation and inhibition based on differences in the salience of the absent cue. Granted, either of these accounts may be inadequate to fully account for the degree to which one sees an asymmetry between extinction of excitation and extinction of inhibition, but we offer them as speculative accounts that remain to be tested. In any case, in the present experiments we have demonstrated that conditioned inhibitors are not entirely immune to extinction through exposure of the putative inhibitor alone.
Acknowledgements We thank Doriann Alcaide, Jacob Blattstein, Alana Osroff, and Michelle Satanovsky for comments on an earlier version of this manuscript. This research was supported in part by NIH Award MH033881.

\section{References}

Beatu, I., \& Baker, G. (2010). Extinction and blocking of conditioned inhibition in human causal learning. Learning \& Behavior, 38, 394407. https://doi.org/10.3758/LB.38.4.394

Bouton, M. E., \& Bolles, R. C., (1979). Contextual control of the extinction of conditioned fear. Learning and Motivation, 10, 445-466. https://doi.org/10.1016/0023-9690(79)90057-2

Bouton, M. E., \& King, D. A., (1983). Contextual control of the extinction of conditioned fear: Tests for the associative value of the context. Journal of Experimental Psychology: Animal Behavior Processes, 9, 248-265. https://doi.org/10.1037/0097-7403.9.3.248

Denniston, J. C., Chang, R. C., \& Miller, R. R. (2003). Massive extinction treatment attenuates the renewal effect. Learning and Motivation, 34, 68-86. https://doi.org/10.1016/S0023-9690(02)00508-8

Detke, M. J. (1991). Extinction of sequential conditioned inhibition. Animal Learning \& Behavior, 19, 345-354. https://doi.org/10. 3758/BF03197895

DeVito, P. L., \& Fowler, H. (1986). Effects of contingency violations on the extinction of a conditioned fear inhibitor and a conditioned fear excitor. Journal of Experimental Psychology: Animal Behavior Processes, 12, 99-115.

DeVito, P. L., \& Fowler, H. (1987). Enhancement of conditioned inhibition via an extinction treatment. Animal, Learning \& Behavior. 15, 448-454. https://doi.org/10.3758/BF03205055

Hallam, S. C., Matzel, L. D., Sloat, J. S., Miller, R. R. (1990). Extinction and inhibition as a function of posttraining extinction of the excitatory cue used in Pavlovian inhibition training. Learning and Motivation, 21, 59-84. https://doi.org/10.1016/0023-9690(90) 90004-8

Holland, P. C. (1983). Occasion-setting in Pavlovian feature positive discriminations. In M. L. Commons, R. J. Herrnstein, \& A. R. Wagner (Eds.), Quantitative analysis of behavior: Discrimination Processes. Vol. 4 (pp. 183-206). New York, NY: Ballinger. https:// doi.org/10.3758/BF03200045

Holland, P. C. (1989). Transfer of negative occasion setting and conditioned inhibition across conditioned and unconditioned stimuli. Journal of Experimental Psychology: Animal Behavior Processes, 15, 311-328. https://doi.org/10.3758/BF03213394

Holland, P. C., \& Gory, K. (1986). Extinction of inhibition after serial and simultaneous feature negative discrimination training. Quarterly Journal of Experimental Psychology, 38B, 245-265. https://doi. org/10.1080/14640748608402234

Holland, P. C., \& Lamarre, J. (1984). Transfer of inhibition after serial and simultaneous feature negative discrimination training. Learning and Motivation, 15, 219- 243. https://doi.org/10.1016/0023-9690(84) 90020-1

Lamarre, J., \& Holland, P. C. (1987). Transfer of inhibition after serial feature negative discrimination training. Learning and Motivation, 18, 319-342. https://doi.org/10.1080/14640748608402234

Lotz, A., \& Lachnit, H. (2009). Extinction of conditioned inhibition: Effects of different outcome continua. Learning \& Behavior, 37, 85-94. https://doi.org/10.3758/lb.37.1.85

Lubow, R. E., \& Moore, A. U. (1959). Latent inhibition: The effect of nonreinforced pre-exposure to the conditional stimulus. Journal of Comparative and Physiological Psychology, 52, 415-419. https:// doi.org/10.3758/BF03199940

Lysle, D. T., \& Fowler, F. (1985). Inhibition as a "slave" process: deactivation of conditioned inhibition through excitation of conditioned 
excitation. Journal of Experimental Psychology: Animal Behavior Processes, 11, 71-94. https://doi.org/10.3758/BF03205055

Melchers, K. G., Wolff, S., Lachnit, H. (2006). Extinction of conditioned inhibition through nonreinforced presentation of the inhibitor. Psychonomic Bulletin \& Review,13, 662-667. https://doi.org/10. 3758/BF03193978

Miller, R. R., Barnet, R. C., \& Grahame, N. J. (1995). Assessment of the Rescorla-Wagner model. Psychological Bulletin, 117, 363-386. https://doi.org/10.1037/0033-2909.117.3.363

Miller, R. R., \& Schachtman, T. R. (1985). The several roles of context at the time of retrieval. Context and learning, 167-194.

Pearce, J. M., Nicholas, D. J., \& Dickinson, A. (1982). Loss of associability by a conditioned inhibitor. The Quarterly Journal of Experimental Psychology, 34, 149-162. https://doi.org/10.1080/ 14640748208400883

Pearce, J. M., \& Wilson, P. N. (1991). Effects of extinction with a compound conditioned stimulus. Journal of Experimental Psychology: Animal Behavior Processes, 17, 151-162. https://doi.org/10.3758/ BF03330457

Pavlov, I. P. (1927). Conditioned reflexes. (G. V. Anrep, Ed. \& Trans.) London: Oxford University Press.

Polack, C. W., Laborda, M. A., \& Miller, R. R. (2012). Extinction context as a conditioned inhibitor. Learning \& Behavior, 40, 24-33. https:// doi.org/10.3758/s13420-011-0039-1

Rescorla, R. A. (1969). Pavlovian-conditioned inhibition. Psychological Bulletin, 72, 77-94. https://doi.org/10.1037/h0027760

Rescorla, R. A. (1982). Some consequences of associations between the excitor and the inhibitor in a conditioned inhibition paradigm. Journal of Experimental Psychology: Animal Behavior Processes, 8, 288-298. https://doi.org/10.1037/0097-7403.8.3.288

Rescorla, R. A., \& Wagner, A. R. (1972). A theory of Pavlovian conditioning: Variations in the effectiveness of reinforcement and nonreinforcement. In A. H. Black \& W. F. Prokasy (Eds.), Classical conditioning II: Current theory and research (pp. 64-99). New York, NY: Appleton-Century Crofts.

Robbins, S. J. (1990). Mechanisms underlying spontaneous recovery in autoshaping. Journal of Experimental Psychology: Animal Behavior Processes, 16, 235-249. https://doi.org/10.1037/00977403.16.3.235
Savastano, H. I., Cole, R. P., Barnet, R. C., \& Miller, R. R. (1999). Reconsidering conditioned inhibition. Learning and Motivation, 30, 101-127. https://doi.org/10.1006/lmot.1998.1020

Sosa, R., \& Natali, M. (2019). Conditioned inhibition: Historical critiques and controversies in the light of recent advances. Journal of Experimental Psychology: Animal Learning and Cognition.

Stout, S. C., \& Miller, R. R. (2007). Sometimes competing retrieval (SOCR): A formalization of the comparator hypothesis. Psychological Review, 114, 759-783. https://doi.org/10.1037/ 0033-295X.114.3.759

Urcelay, G. P., \& Miller, R. R. (2006). Counteraction between overshadowing and degraded contingency treatments: Support for the extended comparator hypothesis. Journal of Experimental Psychology. Animal Behavior Processes, 32, 21-32. https://doi.org/ 10.1037/0097-7403.32.1.21

Williams, D. A., \& Overmier, J. B. (1988). Some types of conditioned inhibitors carry collateral excitatory associations. Learning and Motivation, 19, 345-368. https://doi.org/10.1016/0023-9690(88) 90045-8

Williams, D. A., Overmier, J. B. \& LoLordo, V. M. (1992). A reevaluation of Rescorla's early dictums about Pavlovian-conditioned inhibition. Psychological Bulletin, 111, 275-290. https://doi.org/10. 1037/0033-2909.111.2.275

Williams, D. A., Travis, G. M., \& Overmier, J. B. (1986). Withincompound associations modulate the relative effectiveness of differential and Pavlovian-conditioned inhibition procedures. Journal of Experimental Psychology: Animal Behavior Processes, 12, 351362.

Witcher, E. S., Ayres, J. J. (1984). A test of two methods for extinguishing Pavlovian-conditioned inhibition. Animal Learning \& Behavior, 12,149-156. https://doi.org/10.3758/BF03213134

Zimmer-Hart, C. L., \& Rescorla, R. A. (1974). Extinction of a Pavlovian conditioned inhibitor. Journal of Comparative and Physiological Psychology, 86, 837-845. https://doi.org/10.1037/h0036412

Publisher's note Springer Nature remains neutral with regard to jurisdictional claims in published maps and institutional affiliations. 